\title{
COVID pandemic and denosumab adherence
}

\author{
S. Minisola ${ }^{1} \cdot$ C. Cipriani $^{1} \cdot$ E. Vigna ${ }^{1} \cdot$ C. Sonato ${ }^{1} \cdot$ L. Colangelo $^{1} \cdot$ F. Monti $^{1} \cdot$ J. Pepe $^{1}$
}

Received: 6 September 2021 / Accepted: 13 December 2021 / Published online: 23 January 2022

(c) International Osteoporosis Foundation and National Osteoporosis Foundation 2021

Keywords Adherence $\cdot$ COVID $\cdot$ Fracture $\cdot$ Denosumab

The coronavirus (COVID 19) pandemic has brought unprecedented disruptions to the provision of health care in every country of the world. Therefore, a number of measures have been implemented with the aim of containing the spread of the virus, the most dramatic being national lockdowns.

These measures challenged many national health systems, sometimes at the expense of patients with both acute and chronic diseases. For example, in order to counteract difficulties with osteoporosis, the American Society for Bone and Mineral Research provided clinical recommendations based on available evidence [1]. For denosumab, one of the most prescribed antiresorptive agents, the panel of experts "strongly recommend the temporary transition to an oral bisphosphonate for patients in whom continued treatment with denosumab is not feasible within 6 months of their most recent prior denosumab injection". Another paper recommended home administration of denosumab, but this may not be possible in all settings [2].

To the best of our knowledge, there are no reports that have explored the impact of COVID 19 in a real world setting concerning continuation of denosumab treatment and adherence to the ASBMR recommendations. This is of utmost importance because of the well-known deleterious effects that may occur within the first several months following discontinuation. Many studies have shown that following denosumab discontinuation there is accelerated bone turnover, rapid loss of bone mineral density and increased rate of multiple vertebral fracture [3, 4]. Most importantly, a short off-treatment period of 2 to 10 months is enough to produce such catastrophic events [5]. This contrasts with

S. Minisola

salvatore.minisola@uniroma1.it

1 Department of Clinical, Internal, Anaesthesiological and Cardiovascular Sciences, Sapienza University of Rome, Rome, Italy the relatively long-term effect following bisphosphonate withdrawal [6].

Here we report the experience of our referral centre concerning patient behaviour with denosumab adherence, before and during the pandemic period.

Table 1 reports our case series of 20 patients with vertebral fractures following denosumab discontinuation. Main demographic parameters, length of denosumab therapy, date of discontinuation, months elapsed between occurrence of vertebral fracture and denosumab discontinuation and ambulatory presentation are reported. For Italy, March 9, 2020, marked the beginning of the Italian national lockdown that completely limited, until May 4, free circulation. After that, these measures were in part eased, even though some limitations were still in place until June 14, at least in the Lazio region. Restrictive measures were re-imposed in the following periods depending on the number of infected persons, until June 2021.

It can be seen that the number of patients that came to our attention reporting vertebral fractures after denosumab discontinuation dramatically increased during the current year. Indeed, until 2019, we had observed only 8 cases in 7 years; in 2021 (and 2020), we observed 12 cases. According to these last 12 patients, this was mainly due to the inability of adhering to denosumab treatment for a number of reasons, the most important being the inability to access medical facilities during the pandemic period. This was due to mobility restrictions and fear of access to our hospital, selected for the management of COVID patients. We therefore believe that this should be listed among the side effects of the pandemic.

Finally, it is important to note that only patients with symptomatic vertebral fractures came to our attention. It is highly possible that the impact on fracture incidence due the pandemic is even greater than what we observed. 
Table 1 Case series of 20 patients with vertebral fractures following denosumab discontinuation

\begin{tabular}{|c|c|c|c|c|c|c|}
\hline Patient & Sex & Age (years) & $\begin{array}{l}\text { Length of denosumab } \\
\text { therapy (months) }\end{array}$ & Date of discontinuation & $\begin{array}{l}\text { Months interval (occurrence of } \\
\text { fracture vs discontinuation) }\end{array}$ & $\overline{\text { Ambulatory presentation }}$ \\
\hline A. $\mathrm{G}$ & $\mathrm{F}$ & 64 & 42 & February 2018 & 11 & March 2019 \\
\hline A. $R$ & $\mathrm{~F}$ & 63 & 66 & July 2020 & 12 & July 2021 \\
\hline B.P & $\mathrm{F}$ & 75 & 24 & April 2015 & 11 & June 2016 \\
\hline B. L & $\mathrm{F}$ & 65 & 18 & December 2014 & 14 & March 2016 \\
\hline B. A & $\mathrm{F}$ & 83 & 54 & December 2019 & 9 & April 2021 \\
\hline C.A & $\mathrm{F}$ & 60 & 60 & June 2020 & 12 & July 2021 \\
\hline C. P & $\mathrm{F}$ & 59 & 48 & December 2018 & 11 & March 2021 \\
\hline C. G & $\mathrm{F}$ & 69 & 36 & March 2018 & 16 & April 2021 \\
\hline C. L & $\mathrm{F}$ & 60 & 18 & March 2020 & 14 & July 2021 \\
\hline D. L. E & $\mathrm{F}$ & 74 & 24 & September 2013 & 14 & July 2018 \\
\hline D. M & $\mathrm{F}$ & 56 & 66 & July 2018 & 12 & December 2019 \\
\hline F. R & M & 72 & 18 & December 2015 & 14 & May 2018 \\
\hline F. L & $\mathrm{F}$ & 71 & 18 & February 2020 & 15 & May 2021 \\
\hline G. S & $\mathrm{F}$ & 78 & 36 & July 2018 & 12 & July 2019 \\
\hline M. C. L & $\mathrm{F}$ & 67 & 24 & June 2019 & 13 & May 2021 \\
\hline P. T & $\mathrm{F}$ & 79 & 24 & August 2018 & 16 & September 2021 \\
\hline R. A & $\mathrm{F}$ & 73 & 18 & November 2017 & 10 & July 2019 \\
\hline S. P & $\mathrm{F}$ & 70 & 42 & May 2019 & 16 & January 2021 \\
\hline V. M. L & $\mathrm{F}$ & 81 & 30 & July 2019 & 12 & July 2021 \\
\hline V. T & $\mathrm{F}$ & 65 & 36 & March 2019 & 12 & September 2021 \\
\hline
\end{tabular}

Our letter calls attention to the need to emphasize optimal adherence to denosumab therapy and sharing information about discontinuation directly with patients.

Acknowledgements We wish to thank Prof. R. Adler for suggestions and critical review of this letter.

Data availability Upon reasonable request, the data can be shared.

Code availability None.

\section{Declarations}

Conflicts of interest SM served as speaker for Amgen, Bruno Farmaceutici, Diasorin, Eli Lilly, Sandoz, Takeda and Kyowa Kirin. He also served in advisory board of Abiogen, Kyowa Kirin, Pfizer and UCB. Other authors declare no competing interests.

\section{References}

1. Yu EW, Tsourdi E, Clarke BL, Bauer DC, Drake MT (2020) Osteoporosis management in the era of COVID-19. J Bone Miner Res 35:1009-1013
2. Narla RR, Adler RA (2021) Osteoporosis care amidst the prolonged pandemic. J Endocrinol Investig 44:1353-1362

3. McClung MR, Wagman RB, Miller PD, Wang A, Lewiecki EM (2017) Observations following discontinuation of long-term denosumab therapy. Osteoporos Int 28:1723-1732

4. Tsourdi E, Langdahl B, Cohen-Solal M, Aubry-Rozier B, Eriksen EF, Guañabens N, Obermayer-Pietsch B, Ralston SH, Eastell R, Zillikens MC (2017) Discontinuation of denosumab therapy for osteoporosis: a systematic review and position statement by ECTS. Bone 105:11-17

5. Lyu H, Yoshida K, Zhao SS, Wei J, Zeng C, Tedeschi SK, Leder BZ, Lei G, Tang P, Solomon DH (2020) Delayed denosumab injections and fracture risk among patients with osteoporosis: a population-based cohort study. Ann Intern Med 173:516-526

6. Black DM, Reid IR, Boonen S, Bucci-Rechtweg C, Cauley JA, Cosman F, Cummings SR, Hue TF, Lippuner K, Lakatos P, Leung PC, Man Z, Martinez RL, Tan M, Ruzycky ME, Su G, Eastell R (2012) The effect of 3 versus 6 years of zoledronic acid treatment of osteoporosis: a randomized extension to the HORIZON-Pivotal Fracture Trial (PFT). J Bone Miner Res 27:243-254

Publisher's note Springer Nature remains neutral with regard to jurisdictional claims in published maps and institutional affiliations. 